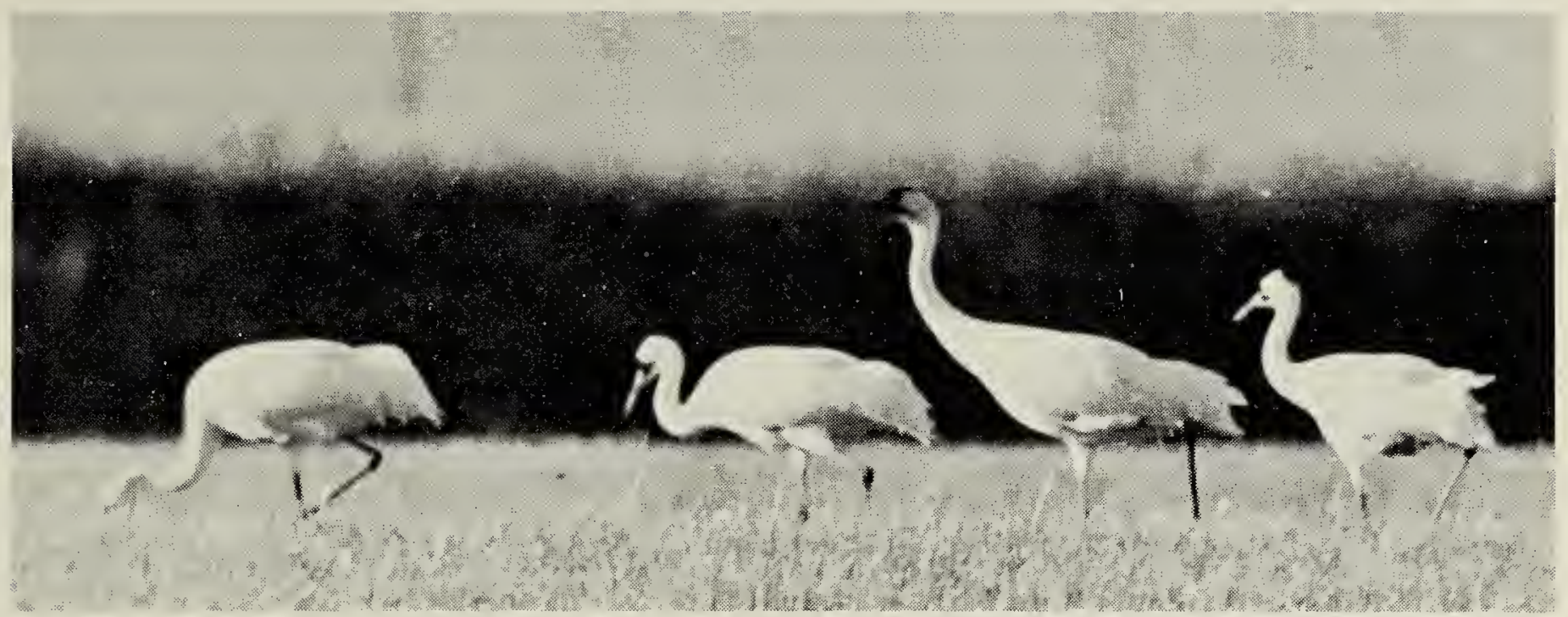

Photo by Fred G. Bard, Saskatchewan Museum of Natural History

Whooping Crane family at Moose Jaw, October, 1965

\title{
WHOOPING CRANE POPULATION REPORT
}

On December 29, 1965, the U.S. Fish and Wildlife Service released the following information: "The fall migration of wild whooping cranes apparently is complete, and a record high of 44 whoopers is wintering at the Aransas National Wildlife Refuge in Texas, Secretary of the Interior Stewart L. Udall announced today. Of the 44 birds now at Aransas, eight are young-of-the-year-easily distinguished by the buff coloration of head and neck - and 36 are adults. The number of adults represents a loss of six mature birds from the total of 42 wild whoopers last year. One dead crane was found in western Kansas November 8. Evidence indicates the bird, an 18-month - old mate, was killed when he struck a power line. Because the whooping cranes nest in a wilderness area in the vicinity of Canada's Wood Buffalo National Park, the fate of the five other missing adults may never be known.

"The whooper vanguard of two adults arrived at the refuge sometime during the night of October 21. On an aerial survey, October 26, Refuge employees counted 15 birds, including three youngsters. There were 24 birds - 19 adults and five young-on November 2 ; 36 , including eight young birds, on November 10 ; 31 adults and seven young on Novem- ber 21; and a total of 44 birds on November 23. [We are interested in the increased number reported for November, since four birds that remained for approximately two weeks in stubble field's north of Moose Jaw left for the south on October 30.]

"Only 14 whooping cranes were in the wild flock when record keeping began in the winter of 1938-39 on the then newly established Aransas $\mathrm{Na-}$ tional Wildlife Refuge. The population rose to 26 in 1940-41, but dropped sharply to 15 the following year. There was a gradual increase to 34 in 1949-50, dropping again to 21 in 1954-55. After several years of fluctuating gains and losses, the whooper population reached a high of 38 in 1961-62. The following year, disaster struck. Six birds were lost to unknown causes and, for the second time since 1938, no young birds were produced. Thirty-two birds migrated north in the spring of 1964 . These 32 brought 10 young-of-the-year with them when they returned to the Aransas Refuge in the fall of 1964.

"There are also seven whooping cranes in captivity. Six of these are at the Audubon Park Zoo in New Orleans and one, the injured Canus which was rescued from the Canadian wilds, is at the Monte Vista National Wildlife Refuge in Colorado." 